\title{
Challenges of the Knowledge Based Economy in East Asia
}

\author{
Virachai Vongbunsin, John Walsh \\ Shinawatra University, Bangkok, Thailand \\ jcwalsh100@hotmail.com
}

\begin{abstract}
The knowledge-based economy (KBE) is widely considered to be the foundation of the next stage of economic growth, following agriculture, manufacturing and services. Countries seeking to enter the KBE must take care to ensure that their resources 'particularly human resources ' are willing and able to fulfil the roles requested of them. That in turn means that countries must be aware of what challenges and difficulties they will face in taking this next step in development. This paper attempts to outline at the macro-social level the issues involved in this process with a view to identifying an agenda of state-level developmental goals to be tackled.
\end{abstract}

Keywords: Knowledge based economy, economic growth, East Asia

\section{Introduction}

Inspired by the work of Hofstede $(1980 ; 1984 ; 2010)$, attempts have been made to characterize states by aggregate constructs and relate these to social and economic development factors in those states. Khalil and Marouf (2015), for example, found the uncertainty avoidance, future orientation, institutional collectivism and performance orientation all exhibited positive influences on the ability of the state to be ready to embrace the knowledge-based economy (KBE). Cultural factors are not the only ones to have an influence on ability to embrace the KBE. Institutional factors within a country have been found to be relevant (Andrés, Asongu \& Amavilah, 2015) and the competencies and agility of firms in taking advantage of innovations (Scuotto \& Shukla, 2015; Gausdal, 2015). At a time of rapid regional integration, as witnessed by the initiation of new phases of the ASEAN Economic Community (AEC), the need for economies to open themselves to the benefits of the KBE becomes more imperative. Consequently, this paper seeks to evaluate the nature and scope of the KBE in the East Asian context and makes some assessments concerning how well countries are prepared for the challenges ahead. Definitions of the KBE are often difficult to pin down because they rely on an understanding of what knowledge is that has itself not been properly defined (Brinkley, 2006). This has led to a number of problems with comparing figures across countries or even across industries within the same country because of differences in definitions and practice. For example, according to the Thai government, the majority of activities taking place within the country's knowledge economy both by volume of activities and by value come from jewellery manufacturing by industry workers (Kenan Institute, 2009).

However, this understanding is quite different from the general understanding of what knowledge generation in work should be. Consequently, it is necessary to provide a definition of the knowledge-based economy (KBE) that is sufficiently broad as to be useful for outlining the different ways in which it should be managed. The concept of the importance of knowledge in the economy has been recognized for many years - Marx wrote about it, for example - but it was not until the middle of the twentieth-century that it started to become a focus of attention for those involved in studying organizations, particularly firms, and their role in the development of economies and societies. At this time, the knowledge was mainly considered to be a function of the composition to improve the quality of education of young people going in to the workforce. Some efforts were made to try to match the skills and competencies of the workplace entrants with what industry might require through the use of vocational schools and technical colleges. However, such efforts to match supply and demand for skills in East Asia have generally been unsatisfactory for several reasons:

- Lack of technical capacity and ability to provide the kinds of industry-specific skills required; 
- Strong preference in society for a Confucian view of education for a young persona but takes the view that most prestigious type of education is university-based in a strictly hierarchical system of universities with preference for a comparatively small number of academic subjects;

- Labour market systems are set up to reward the level of qualifications individuals possess when they enter the workplace and receive annual incremental salary increases that maintain the differentials established at entry throughout the career of individuals.

As a result of these issues, labour market systems have been established in Japan and South Korea in particular in which, post-graduation, young people are integrated into the large companies on the understanding (sometimes contractual in nature) that they will work with those companies on an extended period of time, even to the extent of taking up lifetime employment. The reason for this is that it is accepted by the employer that the new entrant will have little actual value in the workplace at first but does have the potential to contribute over the long-term because they can learn both on-the-job and during their period of employment generally. Mincer (1962) observes of on-the-job training that it ranges from formally organized activities such as apprenticeships and other training programs to the formal processes of learning from experience. He went on to observe that, historically, nearly all skills have been learned on the job and the delayed entry into the workplace represented by lengthy secondary and tertiary levels of education are recent innovations which do not necessarily provide skills or knowledge that are directly transferable to the workplace.

It is clear, then, that this early conception of the importance of knowledge in economic activities depended on a static situation in which the principal issue was the worker's ability to complete the work allocated effectively. To become effective meant learning the use of the tools, systems and so forth that everybody else also used. This is a system that was well-suited to an economy in which demand exceeded supply and it was the role of factories to produce what goods they were able to produce at maximum output knowing there were customers ready to buy them and, if there should be some kind of failure and foods were left unsold, salespeople could be hired to solve the problem. However, in the contemporary world, this situation has changed significantly:

- In most consumer goods in particular, there is now an excess of supply over demand, meaning customers are unwilling to accept second or third preferences;

- Further, manufacturing technology has developed to the point that small batch processes can provide variations according to taste to customers willing to pay a premium for the service;

- This variation is further required because of the spread of international production and consumption around the world, meaning that more cultural and historical factors have to be incorporated into production decisions.

In this situation, it is evident that workers simply learning how to use tools to make a specific product are insufficient to the needs of a modern company. At the very least, they must be able and willing to adapt themselves to changing systems and the need to find ways to change production methods in short periods of time - the same is true of service sector activities as well as the manufacturing sector. The accelerated speed with which it is necessary to act - because of shortening product life cycles and the increased choice available to most consumers - make it more important than ever that workers understand their role and their ability to contribute to the company as a whole through improving the production process and matching it to customer demand. To do so, they must make use of two types of knowledge, explicit knowledge and tacit knowledge:

- Explicit knowledge: this is the type of knowledge that is externally expressed (written or digitized) and so available to anyone given access and usually organized in a rational and sequential process. It can cover theoretical issues where these are relevant;

- Tacit knowledge: this is the kind of knowledge that is not written down for some reason but has to be obtained by the individual through practical experience and relates theory to pragmatic observation. It relates theoretical issues to how they work in practice and they include all kinds of interpersonal details, relationships and histories that are never recorded officially (Nonaka \& Takeuchi, 1995).

Since it takes time for employees to learn all this knowledge -even to find out what kind of knowledge it is necessary to learn - as well as to keep abreast of any changes, it is apparent that the longer the individual 
remains with a company, the more valuable that individual is to the company. Insofar as the individuals involved are aware of their enhanced value, they might expect to receive seniority-based salary increases. This is a situation that can be problematic in that it can make a small number of people apparently irreplaceable and lead to bottlenecks in decision-making. Managing such situations is to some extent what justifies the high salaries that HR managers these days are able to command. This paper outlines the nature of the KBE in East Asia and considers topics such as the educational aspirations of East Asian students and their parents, the business schools and universities of the region in comparative perspective and the importance of intellectual property rights and the threat of intellectual piracy.

What Is Information? The nature and extent of information have increased enormously in recent years. Business information used to be confined to the presence and cost of various commodities and the people interested in buying or selling them. This was usually specialized information that would be expensive and kept secret where possible. Traders and commerce were regulated by the state, especially in the sinicized countries and networks competed with each other. People who lived in places of production had an incentive to attract more traders so as to increase demand and, hence, prices and this conflicted with the interests of the merchants. Business information of this sort became part of the tradable system. During the period of colonization, local knowledge started to become commodified on a large scale as newly arrived explorers and would-be traders sought new markets and the best way to reach them. The various attempts to find a southern passage to China via Burma or the River Mekong, for example, witnessed local people being grilled for knowledge and converted into guides to help in achieving business goals. In due course, all parts of colonized lands became important to be known, mapped and categorized both to facilitate control of those territories but also to convert them into taxable items. After the Japanese occupation of Taiwan, for example, the people were subjected to a range of censuses and surveys aimed at developing knowledge, understanding and control of the Japanese people (Yao, 2006:37-61). The purpose of this knowledge generation may initially have been bureaucratic-administrative in nature but soon the commercial applications became apparent. In the contemporary business world, it is very obvious that the creation of an accurate database of potential customers is a worthwhile commercial activity in its own right. As the number of personal computers and similar equipment has multiplied, people spend increasing amounts of time online and they provide all kinds of commercially-valuable information about themselves conveniently collected together for cultivation. People who register with a social networking site such as Hi5 or Facebook, for example, seem happy to reveal their birthdays, the people they consider their friends, their favorite music and movies and all kinds of information about their daily consumption decisions. This information represents a treasure trove for marketers and, indeed, for cyber criminals.

\section{Data and Information}

The ability to collect information and store it for lengthy periods has made it more important than ever to distinguish between information and what is actually only data. Data are points of information or observations that in themselves are of little or no value but which can be useful if processed and presented appropriately. For example, barcode technology makes it possible for shopkeepers automatically to record every occasion when an item is purchased at the same time. All of this data is recorded by the scanner attached to the cash register and placed in computer storage. In this state, it is data of no real value. However, if someone then analyses the data to find out that, for example, people are more likely to buy large sacks of rice at the weekend or that those who buy instant noodles are also likely to buy kimchi at the same time, then this becomes useful information that can be used to create successful point of sale promotions. Information, then, is data refined to a specific purpose. Usually, it would be expected that it must be people involved with the process of converting data into information but this need no longer be the case. Software programs exist which can be launched and which will semi-intelligently work their way through means of data searching for structures and patterns in a process known as 'data mining.' There are so many new batches of data being created every hour or every day that it is not feasible to imagine there being enough time to analyze it all. However, computing power has increased so much that it is possible to use machines and programs to lead the way with Knowledge Discovery in Databases (KDD) (Fayyad, Piatetsky-Shapiro \& Smyth, 1996).

In some cases, curators of scientific databases have turned to citizen science to assist in the KDD: starting with the Search for Extra-Terrestrial Intelligence (SETI) located in California, datasets have been made freely 
available for members of the public to download and their computers run the relevant programs when they are not otherwise occupied. This model offers an opportunity for research institutes to obtain some datamining support for their work, even if it appears that the ability to record new observations is matching the increasing capacity to analyze them. The point is that the initial parameters set can be used to guide the way that data mining is conducted and results can be uploaded automatically during any period when the machine is idle but an active internet connection is available. The parameters can also be varied by a simple download and the user can select her own degree of involvement in any changes made. Of course, this is a similar model to that which is used by cyber criminals using viruses to turn users' machines into zombies delivering plague around the world. KDD has many applications in the business world, ranging from marketing to manufacturing to finance. In each case, large databases of observations are analyzed in the hope of identifying patterns of data which are non-random in nature and to which meaning can be attached. The difference between data-mining and KDD is the difference between the launching of the algorithm on the database and the set of processes necessary to define and collate the database and assess and deal with the findings. So, while data mining might be sufficient to identify matching sequences of numbers that might indicate credit card fraud, KDD is required to search for opportunities to improve manufacturing efficiency and possible quality improvements in an operational database.

One important area for KDD has become that of customer relationship management (CRM). Depending on the nature of the relationship between company and customer, a wide variety of data may be collected by the former on the latter. Some of that information might prove to be useful in improving the relationship between the two or else in terms of increasing potential sales. Salespeople will be familiar with the double diary technique: one diary is used in the normal way to record meetings and contact details, while the second diary is used to keep information about prospects (e.g. married, golf-player) which might be gleaned from a meeting and which can be used in any subsequent meeting to try to demonstrate an interest in the customer as an individual. This process can be computerized and can add automated telephone or SMS reminders about appointment, messages of thanks and the like.

Business Information Systems: Business Information Systems (BIS) are technological systems that enable managers to make the best use of the information they possess. They are related to other information systems that provide assistance to management in understanding the external environment and analyzing changes with a view to obtaining competitive advantage. Such systems include knowledge management systems, on-line analytical processing systems, decision-support systems and executive information systems (Thierauf, 2001). Knowledge management systems are means of collating and managing information available to an organisation, including such items as tacit knowledge used in production and information about customers and other important stakeholders. One aspect of a knowledge management system is the customer relationship management (CRM) approach, which aims to systematize and computerize as far as possible every form of interaction between the company and stakeholders and both make the relevant information available to employers involved in subsequent interactions and, also, to structure decisions about the stakeholder that might be made. CRM originated in the IT sector and was initially seen as a possible solution to the cost-saving desire for computerized sales force automation. However, it has subsequently been seen as a central plank of the strategically-minded marketing department and its role in driving shareholder value as a whole (Payne \& Frow, 2005).

While CRM has proven to be useful in some sectors, the claims made for it have not always come true and there are many customers who have resisted the use of automated systems to sell additional items to the. It is necessary for marketers to appreciate the unprecedented and indeed previously unimaginable increase in the number of interactions that individuals now have with both automated systems and with commercial transactions. Research indicates the CRM improvements in business objectives tend to be relatively modest (Verhoef, 2003) and are difficult to sustain when human interactions are involved. Nevertheless, CRM has burgeoned into a flourishing industry and has many proponents and exponents. For example, Taiwan's largest baby and children's wear manufacturer, Les Enphants, was founded in Taipei in 1971 and now supplies not just shops but its own tourist factory, where interactive features enable children to discover the joy of designing and making clothes. The company also distributes a number of other internationally renowned child fashion brands (e.g. Oshkosh B'gosh, Armani Junior, Combi) and in retail spaces ensures that 
a number of CRM systems are convenient to record customer feedback, market trends and the nature of customer demand (Her, 2012).

On-line analytical processing systems (OLAP) are software tools that enable users to address multidimensional analytical questions. Business data are recorded from a variety of different perspectives: retail sales data, marketing and advertising support and effectiveness data, manufacturing productivity and costs and so forth. All of these sources of data are aggregated, since each one might singly or in combination with others provide insights of use to managers or researchers. OLAP tools can use either the totality of the data, the smallest level of data collection or some subset of the data specifically designed for interrogation of a particular problem. For example, researchers in Japan created a database ('warehouse') of various kinds of information recorded in different departments and institutions that could then be used to identify and match patient identity and care and medical conditions data (Akinobu et al., 2003). These advanced computations yield results that can then be viewed using a technology as straightforward as Microsoft Excel, which is important in that it broadens the number of managers capable of using and acting on the data analysis.

\section{East Asia and Educational Aspirations}

East Asia has, generally, long had an excellent reputation for the educational aptitude of its students, particularly those societies which have a strong Confucian tradition and in the more quantitative mathematical and scientific skills. To some extent, this results from the historical tradition of the imperial examinations system. In China and Vietnam, in particular, all boys were theoretically able to take the examination, which was based on memorising the classics of literature and history, calligraphy and other skills. Successful candidates, in an intensely competitive environment, could find themselves elevated into a high bureaucratic position and, further, their entire family could be elevated alongside them (Elman, 2000). The tradition of educational achievement has persisted into the modern age and has led to generations of parents placing pressure on their children to achieve the highest possible levels to enter the best schools and universities.

One of the principal purposes of the imperial examination system was the desire to introduce social mobility by offering talented young boys the opportunity to raise their families to a higher level. This also implied, of course, that some at least of those at the top level had to vacate their positions and move down, almost certainly involuntarily. That some degree of competition among East Asian students and their parents has continued to the present day and there are numerous stories in the public media concerning the lengths to which Japanese and Korean families will go to try to get their children into prestigious schools. The hypercompetitiveness of the Chinese parents entering a world in which such competition is becoming a lifelong phenomenon has even reached the point of self-parody. Chinese-American mother Amy Chua, for example, provided an extensive account of her relationship with her daughters and how she tried to regulate every waking moment of their lives so as to make them the most potent, high achievers possible (Chua, 2011).

The high level of competitiveness has contributed to some very high standards in East Asian schools in which, most commonly, middle and upper class children have been admitted. These standards are generally higher in subjects such as science and mathematics which focus on quantitative skills and which are generally considered to be more prestigious in the region and, hence, lead to better careers. Numerous studies have been conducted to try to identify some kind of essentialist factors which distinguish between children of different ethnicities. Irrespective of these studies, the preference for a small range of specific skills has led to some structural problems in East Asian labour markets. Notable among these problems is the concentration of much of the best talent into a very narrow range of activities in which the most talented graduates are concentrated in those activities for which there may not be a great deal of market demand but there will, nevertheless, be an expectation that high salaries and prestige will accompany them. As a result, other career options will be less-well regarded and will attract, in general, people of less talent. In countries which have a formal labour market plan that includes powerful incentives to match supply and demand in the market place, some of these structural problems can be addressed. However, most East Asian states do not have formal labour market plans of this kind. 
An additional feature of the importance with which education is treated in East Asia is the extent to which opportunities are provided for investment and business. The English language market across the region is enormous and provides opportunities for teachers (formally trained or not), textbook publishers, language school entrepreneurs and providers of technical education in fields not yet widely covered in the region. While East Asian states import large amounts of education services from western nations (including the export of throngs of students for overseas education), sometimes the process is reversed. Thailand has, for example, successfully exported therapeutic massage, meditation and cookery lessons, while many people have found it desirable to try to learn to be a sushi chef or martial art exponent.

The Importance of Learning and Education: A recent study by the World Bank (2012) found that, despite impressive gains having already being made; higher education could be making additional contributions to economic growth in East Asia. The report went on to describe five 'disconnects' that are acting as constraints to further growth:

- a gap between education institutions and the skill needs of employers;

- a weak research and technology nexus between higher education institutions and companies;

- a separation between teaching and research institutions (or more generally teaching and research functions);

- a disconnect between higher education institutions themselves and between these providers and training providers;

- A separation between higher education institutions and earlier education institutions (schools) (ibid: 2).

A number of these problems have resulted from, at least in part, the distortions in the labour market caused by cultural and prestige factors as mentioned above. To some extent, market incentives alone will be sufficient to encourage students to move to the newer fields that will accommodate them better, although this process would be more effective with government or social support. For example, the Korean government made strong and coherent efforts to support the computer games industry (particularly the online sector) after it recognised that this would be a strategically importance industrial sector of the future. Such support included:

- coherent and well-resourced institutional support for the industry, responsibility for setting legislation, monitoring companies and providing training and resources for the private sector as needed;

- establishing career paths for graduates wishing to pursue games programming and design to move smoothly from educational institutes to the private sector;

- Raising the status of computer games within society by helping organise and support a competitive league of teams in specific games and ensuring extensive and positive media coverage (Walsh \& Techavimol, 2009).

This regime of support included the essential areas of good policies, education and social solidarity. Providing support in all three of these areas is one of the best ways for government to try to enact industrial policy of this sort.

Business Schools and Learning: One of the principal means of spreading international best practice in the business world is the business school. The number and quality of business schools in East Asia has increased enormously over the past 40 years and there appears to be an almost inexhaustible demand for acquiring business based degrees at both undergraduate and graduate levels. This may be attributed to some extent to the propensity for education in the region as a whole and the recognition of business as a means of finding better income opportunities in the future. Yet the trend seems to go beyond this, since bookstores are full of business self-help volumes of one sort or another and, even in societies in which reading is little appreciated, people may be found on public transportation consulting those books in different formats. Many East Asian languages do not have a word for 'reading' that is separate from 'studying' and this indicates the lack of the concept of reading for pleasure and also perhaps explains the comparatively low levels of popular fiction in many parts of the region. Since people read for self-advancement or self-improvement, any reading material should be virtuous such as Buddhist meditation or business sense development. 
Analysis of the personnel of boards of listed companies in East Asia reveals that the majority of people have at least some international exposure and, very often, experience of business education in an international context (Walsh \& Sentell, 2008). This factor reduces the culturally-specific nature of any particular organization as it has the tendency to migrate towards international best practice. This has been made possible by the fact that business schools themselves now have the opportunity to teach international standard business education because the curriculum and teaching styles have effectively become globalised. Although there are of course some variations in quality and level of educational support, it is reasonable to suppose that a reputable business school anywhere in East Asia is providing a very similar level of knowledge and understanding to what might be available at the most expensive and prestigious universities in Western Europe and the USA.

World's Best Universities: Asia: The US News World's Best Universities Rankings based on the QS World University Rankings, available at: http://www.usnews.com/education/worlds-best-universitiesrankings/best-universities-in-asia (2012).

Table 1: World's Best Universities, Asian Region

\begin{tabular}{|c|c|c|c|c|}
\hline Position & Name & Country & $\begin{array}{c}\text { Score } \\
(\max 100)\end{array}$ & $\begin{array}{l}\text { Worldwide } \\
\text { Position }\end{array}$ \\
\hline 1 & $\begin{array}{l}\text { Hong Kong University of Science and } \\
\text { Technology }\end{array}$ & Hong Kong & 100 & 40 \\
\hline 2 & University of Hong Kong & Hong Kong & 99.8 & 22 \\
\hline 3 & National University of Singapore & Singapore & 99.3 & 28 \\
\hline 4 & University of Tokyo & Japan & 97.4 & 25 \\
\hline 5 & Chinese University of Hong Kong & Hong Kong & 97.2 & 37 \\
\hline 6 & Seoul National University & Korea & 96.9 & 42 \\
\hline 7 & Kyoto University & Japan & 96.3 & 32 \\
\hline 8 & Osaka University & Japan & 96.1 & 45 \\
\hline $9=$ & Tohoku University & Japan & 94.3 & 70 \\
\hline $9=$ & Tokyo Institute of Technology & Japan & 94.3 & 57 \\
\hline 11 & $\begin{array}{l}\text { Korea Advanced Institute of Science and } \\
\text { Technology }\end{array}$ & Korea & 94.2 & 90 \\
\hline 12 & $\begin{array}{l}\text { Pohang University of Science and } \\
\text { Technology }\end{array}$ & Korea & 93.6 & 98 \\
\hline 13 & Peking University & China & 93.3 & 46 \\
\hline 14 & Nagoya University & Japan & 92.8 & 80 \\
\hline 15 & City University of Hong Kong & Hong Kong & 91.2 & 110 \\
\hline
\end{tabular}

Table 2: Number of Universities in the Top 100 by Country

\begin{tabular}{lll}
\hline Position & Country & Number of Universities \\
\hline $\mathbf{1}$ & Japan & 26 \\
$\mathbf{2}$ & Korea & 16 \\
$\mathbf{3}$ & China & 14 \\
$\mathbf{4}$ & Taiwan & 11 \\
$\mathbf{5}$ & India & 8 \\
$\mathbf{6}$ & Hong Kong & 6 \\
$\mathbf{7 =}$ & Malaysia & 5 \\
$\mathbf{7 =}$ & Thailand & 5 \\
$\mathbf{9}$ & Indonesia & 4 \\
$\mathbf{1 0}=$ & Philippines & 2 \\
$\mathbf{1 0}=$ & Singapore & 2 \\
$\mathbf{1 2}$ & Pakistan & 1 \\
\hline
\end{tabular}


It might be noted that lists of best universities are notoriously controversial and, it may be argued, unreliable because there are so many different ways $n$ which measurement may be tackled: quality of teaching, research output, grants attracted, service to the community and so forth. There are also problems related to unevenness within the universities concerned - some schools or departments might be ranked completely differently from other departments in the same university. In some cases, the quality of students graduating from a university or college might depend to a considerable extent on the ability of the institution to attract high-quality students to enlist there. In other words, lists of best universities should be considered with some caution and possibly a grain of salt.

The Smart City: A smart city is one which integrates the different systems necessary for an urban settlement to have zero carbon dioxide emissions while still maintaining a high level quality of life. Organizing all the different systems involved is quite complex and it would be more convenient, at the present, to create new settlements rather than reconfigure existing ones. However, this is not always possible and it is in any case a necessary step for progress to be made and it is one that is being taken in the Japanese city of Kitakyushu. The city as a whole consists of more than one million people located in the southern prefecture of Fukuoka, where one of the principal employers is Nippon Steel. As part of its regular methods of production, the steel industry produces some 500 million cubic metres of hydrogen gas annually as a by-product. Using this gas for generating heat within households is one of the principal energy management strategies to be employed in Kitakyushu. Japan, in common with the rest of North-East Asia, lacks access to its own resources of oil and gas and must import them from the Middle east and elsewhere, which is both expensive and energy inefficient. One important alternative which has been employed in the country, nuclear energy, is always controversial in Japan, which is the only country in the world to have been attacked with atomic weapons. That level of controversy multiplied in the wake of the March 2011 earthquake and tsunami, which led to a major incident with one of the three reactors of the Fukushima nuclear power plant. The long-term health implications of this disaster have still not become clear but the urgency with which alternative sources of energy are being sought has become more evident. In the case of Kitakyushu, therefore, that alternative will chiefly be hydrogen and recharging stations are being located throughout the area. This will fuel homes and also cars, since modern cars can now travel up to $600 \mathrm{~km}$ on the basis of ten minutes of charging.

Householders will also be encouraged to use solar panels for roof-top use and these, if the problem of the initial expense can be resolved, will feed into a sophisticated system in which low energy-usage eco-houses will draw power from the grid to supplement hydrogen and solar energy according to a flexible pricing structure depending on variable demand throughout the day. Additional utilities treated to the smart approach include water provision and waste disposal. The aim for water treatment is to make used water into potable water through the use of membrane bioreactors, ultra-filtration membrane systems and reverse osmosis. These technologies have successfully produced clean water from water used by industry and seaweed, although regulations currently prevent it from being used for drinking purposes. Waste treatment features extensive use of recycling to the extent that cars are now broken down completely, with considerable disassembly or previously assembled components and crushing of the remainder into a $600 \mathrm{~kg}$ cube which is them sent to a smelting plant for reuse. Kitakyushu has also become a centre for a cluster of industries working with smart technologies. They have together helped to create a model which is being applied to dozens of other sites in Japan and certain technologies, especially the water cleaning treatments, has been profitably exported to the Middle East and elsewhere. For an individual country, therefore, the creation of a smart city can be of value not just for the benefit of elevated standards of living for its citizens and the overall environmental impact but also for the financial compensations that might be received. Eventually, of course, profitability from exporting will decline because existing technology will mature and be diffused around the world. That will require a continuous effort in $R \& D$ and suitable investment in public and private sector institutions (Thapanachai, 2012).

\section{Intellectual Property Rights and TRIPS}

The World Trade Organization (WTO) defines intellectual property rights (IPR) as: "Intellectual property rights are the rights given to persons over the creations of their minds. They usually give the creator an exclusive right over the use of his/her creation for a certain period of time (WTO, 2011)." It goes on to say that IPR are usually divided into two areas, which are copyright related issues and industrial issues. 
Copyright issues deal with the rights of producers of intellectual content (e.g. songs, books and videos) or of performers or broadcasters of those works to protection from other people using that content without express permission and, if necessary, paying an appropriate fee. The purpose of this form of IPR is said to be "to encourage and reward creative work." This is rather a new concept, since historically people had been free to use intellectual creations in whichever way they saw fit in their own productions. Shakespeare, for example, happily drew upon ideas and stories that had been created by others in their own productions. This was considered standard practice and part of a great tradition of intellectual creativity. Stories, once created, were released into the world and became clay for others to work upon as they see fit. Poets and artists relied upon the artistic and aesthetic sensibility of patrons and audience members to be able to discern between what is good and what is bad and to reward the purveyors of the former appropriately. This situation changed with the technological changes of the twentieth century, which made it possible for electronic transmission or recording of intellectual productions to be made and to be broadcast for profit by intermediaries. When money became involved, as is generally the case, the question of how profits should be divided became important. In the case of the recorded music industry, the recording artists themselves were principally represented by the record labels, that is, the corporations who pay a fee (usually on a multiproduct exclusive contract basis with the artistes) for intellectual products, ownership of the recorded instance of which is transferred to that company. This usually involved a revenue-sharing scheme, with the relative strength and power of label and artiste determining the relative proportions of the division of revenue.

The recording industry has responded over the years to a series of apparent threats with an attempt to have the challenging behaviour criminalised and to lobby for the law to be used to prosecute supposed miscreants. This has ranged from the use of tape recorders to record music from the radio to the use of peer-to-peer file sharing internet services. In each case, the argument used was that people who were able to obtain the product for 'free' would not buy it in the normal way and, hence, the recording industry would be wrongly deprived of its proper revenue. Further, this would not have just an impact on bottom line profitability but would also negatively impact upon the willingness of the company to invest in future products by researching, developing and promoting new generations of artistes. In some cases, the recording industry has been able to enlist various artistes to support its stance and to try to persuade people that the home copying process was not just illegal but also immoral and personally damaging to the artistes involved. It has not just been the recording industry that has been involved, although it has been prominent in the campaign. In addition, producers of books, television programs, feature films, video games and software any other intellectual content that may be transmitted via the internet or a less advanced but illicit distribution channel. The principal means by which IPR are administered in international trade are provided by the WTO's Agreement on Trade-Related Aspects of Intellectual Property Rights, which is commonly known by the acronym TRIPS. This agreement concerns protection of IPR in commercial production as it is expressed in a variety of formats. Information in the following section is drawn from WTO (2012).

Copyright: this is the right of an author or creator of some form of IP to have the exclusive use of that property and for any reference to it by another person or organization to cite the owner properly and, in some cases, pay any license fees for the temporary use of the property. When Bill Clinton's autobiography and the Harry Potter novels were due to be published, reports emerged that faked versions had already been published in China, which would be a clear case of copyright violation. Copyright also includes related rights to the performance or enactment of the IP concerned. Owners of IP have the exclusive right to perform or reproduce those productions for gain - it is genuinely considered acceptable for people to sing other people's songs at home or even in public, although the situation may be different if money changes hands as a result.

Trademarks: a trademark is any combination of graphics and text used to indicate a specific product, service, brand or organization which represents a form of IP. Some trademarks are obvious and well-known, for example Toyota and Honda vehicles are immediately recognizable. Others are less well-known and may be subject to geographic limitation: the picture of a smiling fish, for example, is well-known in Thailand as the brand of a range of snack goods. However, it is not recognized outside of the country. In recent years, a number of local competitors have tried to obtain benefits by association with famous international brands by creating 'MacBurgers,' 'Donald's Burgers' and so forth. However, this phenomenon has largely burned itself out as consumers have become more familiar with the genuine products and are less likely to accept 
substandard substitutes. Brand owners themselves have also been active in placing pressure on host governments to end such unfair competition.

Geographical indications: some products are so closely associated with particular geographic regions that people will be prepared to pay a premium for what is considered to be the original and authentic version. These geographical indications might be quite vague in nature - e.g. Hokkaido scallops or Thai durian - while others may be specific and deliberately caused. In any case, this indicator is now considered to be an important part of IP and it is illegal to claim such an association when one does not exist.

Industrial designs: industrial design involves the use of artistic techniques and engineering skill to create products which may be not just aesthetically pleasing and easy-to-use but also distinctive of a particular company. Much of the litigation between rival mobile (cell) telephone producers in recent years has focused on the extent to which designed features of a device - the position and shape of buttons, the means of interacting with the screen and so on - may actually be considered to be IP-protected industrial design elements.

Patents: a patent is a form of IP that marks the inventor or creator of a product or process or some other definable form of information. Patents are licensed in specific territories for specific periods of time and protection is accorded by the law in return for public disclosure of the IP concerned - after the patent elapses, therefore, anyone can use the previously patented information in their own products. The number of patents registered by people in particular countries is considered to be an important indicator of the KBE.

Layout-designs of integrated circuits: miniaturization of computer equipment has revolutionized consumer electronic goods and the computational power of such items has progressed to the extent that it is now considered feasible for mobile telephones to be used in space as machines to control satellites, collect data and provide useful communication media (Amos, 2011). Critical factors of size and weight to sophistication in such devices can rely upon the architecture of integrated circuits and so it has been determined to be a form of IP that should be protected.

Undisclosed information: the extent to which commercial organizations have been able to influence legal systems for their own benefit is perhaps indicated by the fact that large amounts of undisclosed information, including test data and trade secrets (i.e. nearly everything that a company does behind the scenes) have now been declared to be protectable IP. Given that larger companies have more resources both to claim protection of their own information and to try to prosecute anyone they might consider to be misusing it, it is clear that IPR can be used to create barriers to entry in an industry and to prevent new entrants gaining a foothold. It might be noted that most of these issues are very detailed and complex and offer a great deal of highly-paid work for corporate lawyers qualified to practice in the area: for those people with an interest in this subject, this could represent a lucrative career opportunity. The type and extent of competitive advantage that a firm can obtain, whether on a temporary or sustainable basis, has increased significantly as firms have come to understood better the possibilities offered by different forms of business model. As these possibilities have emerged, it is perhaps not surprising that firms have sought to protect their own innovations and processes so as to help preserve their advantage in what might be a very competitive market environment. This may be understandable but it is certainly a change from the past since most rapidly growing East Asian states achieved much of their success by following western countries in ignoring IPR completely and undertaking patent piracy, reverse engineering and similar techniques (Chang, 2002). TRIPS are administered by the World Trade Organization and members which have accepted the agreement are listed as follows.

The TRIPS agreement contains three major areas: the definition of standards on an international basis; the enforcement of IPR protection measures within particular countries and the mechanisms of dispute resolution when agreement cannot be reached between parties. The principle followed in creating and enforcing rules is to provide the minimum that can be agreed upon by all members, with the freedom provided to individual members to add extra measures if they so desire. Experience and observation of international relations demonstrates that, in cases in which countries deal directly with each other, asymmetries of power come into play making sure that large countries (e.g. the USA or China) are generally able to enforce their will on the smaller powers involved. 
However, this has not always occurred and there are examples in which solidarity among smaller powers together with support from the public in developed countries to place pressure effectively on IPR holders. This happened in the case of generic medicines: that is, medicines produced locally that replicate the effects of foreign, branded medicine through parallel production or reverse engineering techniques. When the TRIPS legislation was introduced following the Uruguay Round the tariff reductions in 1995 by the predecessor to the WTO, people in developing countries were suddenly faced with massive increases in the costs of the drugs on which they relied to survive. For example, people receiving drugs for HIV/AIDS found the cost of drugs they needed rising from US $\$ 150$ per year to US $\$ 10,000$ per year. Such a rise represented a death sentence for those affected - and people with a wide range of medical conditions at a less severe level were also forced into similar circumstances. And yet, as Nobel Prize winning economist Joseph Stiglitz has observed, IP varies from other types of property in that there is no cost attached to allowing another person to use it. Economists speak of zero marginal costs or non-rivalrous consumption, while former president of the USA Bill Clinton observed that using one candle to light another does not diminish the light of the first (Stiglitz, 2006).

\section{Table 3: Nation Members of the Trade Related Intellectual Property in Services (TRIPS)}

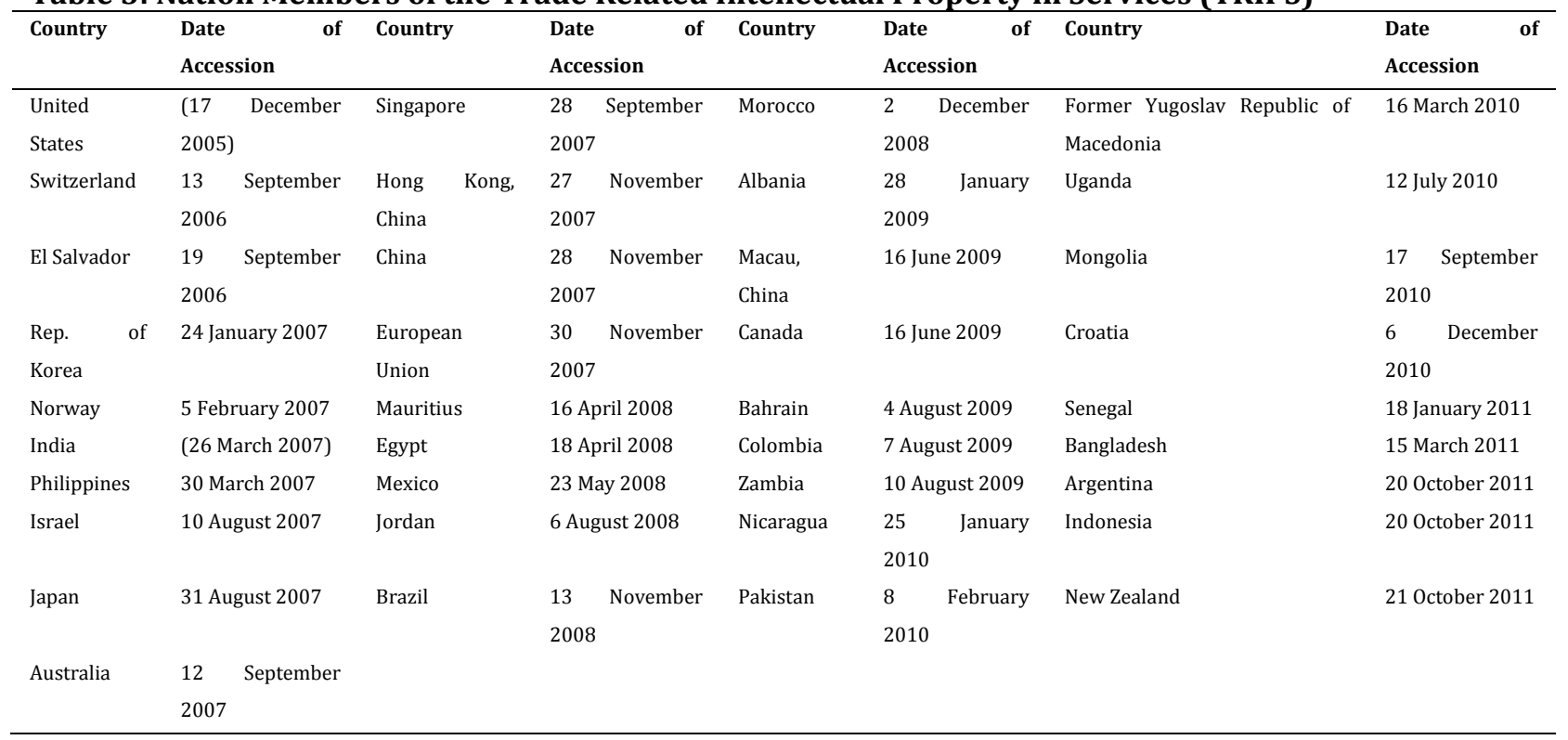

Source: WTO, "Members accepting amendment of the TRIPS Agreement," (2011) available online at: http://www.wto.org/english/tratop_e/trips_e/amendment_e.htm.

Further, control of IPR in an industry such as medicine represents a monopoly which, whether the monopoly power is applied benevolently or malevolently, nevertheless represents a measure of economic inefficiency. In other words, it does not cost anything to pharmaceutical companies to permit the creation and distribution of generic medicines, although it might mean the loss of some unearned income although not, of course, very much because the demand for branded medicine in developing countries is very low. It is also the case that most pharmaceutical companies spend a great deal of their budgets on marketing and advertising rather than scientific research and that most of the profits that they have made have derived from inventions made some decades previously; few companies seem to be inventing important new breakthrough products these days and the cash cows on which they have relied are approaching the end of their protected IPR periods. Since many pharmaceutical companies have also benefited from the effective subsidization of their research by public sector support of universities, it is evident that they are vulnerable to some pressure by governments who can threaten them with the reduction or removal of some of those subsidies. As a result of these factors, diplomatic pressure from the civil society and developing sector governments led, after often fierce rearguard action from the pharmaceutical companies (Glasgow, 2001-2), to an agreement permitting the production of generic medicines under some conditions.

Intellectual Piracy: Intellectual piracy is the process of stealing intellectual property in a direct or indirect manner for the purpose of obtaining financial benefit. This involves such actions as duplicating copyrighted 
items for illegal sale, reverse engineering, incorporating copyrighted material into supposedly original productions, infringing upon registered trade dress or patented material, trading in an assumed name or any other form of acquiring benefit from IP that belongs to another. It is widely believed that, without proper IP protection, there will be widespread copying of that IP and this will lead in the short-term to loss of revenue for owners of the IPR and, in the long-run, much reduced investment in the industry concerned because companies will have a negative incentive to invest in $\mathrm{R} \& \mathrm{D}$ and brand development. As a result, companies involved in the production and distribution of movies, music, books and similar forms of cultural production have generally been keen to enforce IPR around the world and warn that failure to protect them will lead to the collapse of the industry in which they are active. However, it is not entirely clear that such negative effects would actually occur. In the case of the fashion industry, for example, it has been argued that despite the weak IPR regimes available worldwide and the resultant rampant copying and imitation, investment and innovation in the industry remains at a high rate and there is a constant stream of fresh talent willing to break into the sector (Raustiala \& Sprigman, 2006). This rather suggests that the KBE contains a number of industrial sectors which are not dominated by rational, microeconomic decisions but instead contain people wishing to demonstrate their creativity and their desire to participate in an activity for which they have some passion. However, it is necessary to consider the possibility of malicious attacks in cyberspace aimed at a variety of targets, since these have become increasingly prominent part of life and have tended to affect small businesses as much as or more so than individuals.

Implications: As economies follow each other along a trajectory of development that generally moves from agriculture to manufacturing to services and then to knowledge or information, it is evident that it becomes possible for followers to learn from the challenges faced by leaders and the ways that they have sought to overcome them. This implies, therefore, that the followers have taken steps to ensure they are able to benefit from research exploring previous challenges. An openness of the mind, at the national level, is required but it is difficult to put much credence on whether these are available among many of the autocrats that have come to power in various states. A second implication is that it is possible to predict what kinds of skills and competencies that will be required from individuals entering the labour market and, also, those SMEs which will help to facilitate the growth of the KBE. If it is possible to predict, then it is also possible to plan for the future. At various levels of government, therefore, planning units should be seeking to create educational, vocational educational and business development service strategies that are coherent, consistent and properly integrated across all relevant units. In general, such plans are more likely to produce positive outcomes if they seek to motivate individuals concerned through incentives rather than trying to dragoon them into undesired states.

Third, in terms of workplace relations, there is always a temptation for government to yield to corporate interests in enforcing so-called labour reforms aimed at reducing or removing hard-fought protections for workers and employees in terms of job security, freedom of association and right to collective bargaining (these rights are, of course, only available to a limited extent in the East Asia region). Yielding to these temptations will provide some limited short-term increases in profitability but, subsequently, atomization and alienation among the workforce that acts to stifle creativity and quality of service (Huws, 2015). Instead, governments will ultimately be rewarded in terms of social and economic development if they focus on cultivating social solidarity and eliminating the culture of impunity that disfigures various East Asian states. Finally, in an age of globalization which, since the Crisis of Austerity has appeared to be so much less than desirable to millions of people, there is a need to pay attention to those cultural values deemed helpful in terms of embracing the KBE and consider how these might be fostered. In some cases, changes to the regulatory framework might help this come about but it is rather more likely that improvements in the societal and educational realms will bear more fruit.

\section{Conclusion}

It is evident from the preceding analysis that states need to act in a variety of ways in order to prepare their people for the forthcoming KBE. Close coordination between the labour market, the educational system and any mechanisms put into place to promote innovation will be required. It is helpful, in this context, that most East Asian states maintain a basis of approbation for the educational system generally through Confucian and neo-Confucian cultural roots. There is also the confirmed willingness of some states (e.g. Korea and 
Singapore) to make their societies highly connected through online services of a high order. However, there remain difficulties with restrictions on freedom of expression and, consequently, the trust it is necessary to put on the people so as to enable them to be sufficiently creative and innovative as the KBE will require.

\section{References}

Akinobu, Y., Yasutomi, K., Takao, U., Yoshimune, S., Yuka, S. \& Yoshinori, N. (2003). Development of the Medical Care Support System and the Hospital Management Support System Using OLAP Technology. Japan Journal of Medical Informatics, 23(2), 159-164.

Amos, J. (2011). Mobile Phone to Blast into Orbit, BBC News Online (January 24th 2011 ), available at: http://www.bbc.co.uk/news/science-environment-12253228.

Andrés, A. R., Asongu, S. A. \& Amavilah, V. (2015). The Impact of Formal Institutions on Knowledge Economy. Journal of the Knowledge Economy, 6(4), 1034-62.

Brinkley, I. (2006). Defining the Knowledge Economy, The Work Foundation (July, 2006), available at: http://www.theowrkfoundation,com/assets/docs/publications/65_defining\%20knowledge\%20eco nomy.pdf.

Chang, H. (2003). Kicking away the Ladder: Development Strategy in Historical Perspective (London and New York, NY: 2003).

Chua, A. (2011). Battle Hymn of the Tiger Mother (New York, NY: Bloomsbury, 2011).

Elman, B. A. (2000). A Cultural History of Civil Examinations in Late Imperial China (Berkeley and Los Angeles, CA: University of California Press, 2000).

Gausdal, A. H. (2015). Methods for Developing Innovative SME Networks. Journal of the Knowledge Economy, 6(4), 978-1000.

Glasgow, L. J. (2001). Stretching the Limits of Intellectual Property Rights: Has the Pharmaceutical Industry Gone Too Far? IDEA: The Journal of Law and Technology, 41(2), 227-58.

Her, K. (2012). Elephant Dance, Taiwan Review (January 1st, 2012), available at: http://taiwanreview.nat.gov.tw/ct.asp?xItem=182074\&CtNode=1352.

Hofstede, G. (1980). Culture and Organizations. International Studies of Management and Organization, 1, 1541.

Hofstede, G. (1984). Culture's Consequences: International Differences in Work-Related Values, Vol.5 (Thousand Oaks, CA: Sage, 1984).

Hofstede, G., Hofstede, G. J. \& Minkov, M. (2010). Cultures and Organizations: Software of the Brain, third edition (New York, NY: McGraw Hill, 2010).

Huws, U. (2015). Labor in the Global Digital Economy: The Cybertariat Comes of Age (New York, N.Y.: Monthly Review Press, 2015).

Kenan Institute Asia. (2009). Economic contributions of Thailand's creative industries: Final report. Kenan Institute Asia, Bangkok. Available at: http://www.kiasia.org/userfiles/S\%20CREATIVE\%20INDUSTRIES.pdf.

Khalil, 0. \& Marouf, L. (2015). A Cultural Interpretation of Nation's Readiness for Knowledge Economy. Journal of the Knowledge Economy, 2, 1-30.

Mincer, J. (1962). On-the-Job Training: Costs, Returns and Some Implications. Journal of Political Economy, 70(5), Part 2: Investment in Human Beings (October, 1962), pp.50-79.

Nonaka, I. \& Takeuchi, H. (1995). The Knowledge-Creating Company (Oxford: Oxford University Press, 1995).

Payne, A. \& Frow, P. (2005). A Strategic Framework for Customer Relationship Management. Journal of Marketing, 69(4), 167-76.

Raustiala, K. \& Sprigman, C. (2006). The Piracy Paradox: Innovation and Intellectual Property in Fashion Design, University of Virginia Law School, The John M. Olin Program in Law and Economics, Working Paper Series, No.29 (2006), available at: http://www.bepress.com/cgi/viewcontent.cgi?article=1074.

Scuotto, V. \& Shukla, S. (2015). Being Innovator or 'Imovator:' Current Dilemma. Journal of the Knowledge Economy, 6, 1-16.

Stiglitz, J. E. (2006). Scrooge and Intellectual Property Rights, BMJ, Vol.333, No.7582 (December 23 rd, 2006), pp.1279-80.

Thapanachai, S. (2012). Japan's New Smart City, Bangkok Post (May 14th, 2012), Business B.10.

Thierauf, R. J. (2001). Effective Business Intelligence Systems (Westport, CT: Quorum Books, 2001), p.4. 
Fayyad, U., Piatetsky-Shapiro, G. \& Smyth, P. (1996). From Data Mining ro Knowledge Discovery in Databases. AI Magazine, 17(3), 37-54.

Verhoef, P. C. (2003). Understanding the Effect of Customer Relationship Management Efforts on Customer Retention and Customer Share Development. Journal of Marketing, 67(4), 30-45.

Walsh, J. \& Sentell, G. (2008). The Internationalization of Thai Companies. Paradigm, 12(1), 12-20.

Walsh, J. \& Techavimol, P. (2009). Following the Korean Model: Management of the Online Computer Games Industry in Thailand. GITAM Journal of Management, 7(3), 1-13.

World Bank. (2012). Putting Higher Education to Work: Skills and Research for Growth in East Asia (Washington, DC: World Bank, 2012), available at:

WTO. (2011). What Are Intellectual Property Rights? (2011), available online at: http://www.wto.org/english/tratop_e/trips_e/intel1_e.htm.

WTO (2012). Overview: The TRIPS Agreement (2012), available at: http://www.wto.org/english/tratop_e/trips_e/intel2_e.htm.

Yao, J. (2006). The Japanese Colonial State and Its Form of Knowledge in Taiwan, in Liao Ping-Hui and David Der-Wei Wang, eds., Taiwan under Colonial Rule, 1895-1945 (New York: Columbia University Press, 2006), pp.37-61. 